\title{
Relationships between anti-stigma programme awareness, disclosure comfort and intended help-seeking regarding a mental health problem
}

\author{
Claire Henderson, Emily Robinson, Sara Evans-Lacko and Graham Thornicroft
}

\section{Background}

Anti-stigma programmes should aim to increase disclosure to those who can support someone with a mental health problem and appropriate professional help-seeking.

\section{Aims}

We investigated associations among public awareness of England's Time to Change anti-stigma campaign and: (a) comfort envisaged in disclosing a mental health problem to family and friends; (b) comfort in disclosing to an employer; and (c) intended professional help-seeking from a general practitioner, i.e. a physician working in primary care.

\section{Method}

Using data from a survey of a nationally representative sample of adults, we created separate logistic regression models to test for campaign awareness and other variables as predictors of comfort in disclosure and intended helpseeking.

\section{Results}

We found positive relationships between campaign awareness and comfort in disclosing to family and friends (odds ratio $(\mathrm{OR})=1.27,95 \% \mathrm{Cl} 1.14-1.43$ ) and to a current or prospective employer $(\mathrm{OR}=1.20,95 \% \mathrm{Cl} 1.06-1.35)$; and likelihood of help-seeking ( $O R=1.1895 \% \mathrm{Cl} 1.03-1.36)$.

\section{Conclusions}

Awareness of an anti-stigma campaign was associated with greater comfort in disclosing a mental health problem and intended help-seeking.

\section{Declaration of interest}

S.E.-L. and C.H. have received consulting fees from Lundbeck. S.E.-L. currently holds a Starting Grant from the European Research Council. G.T. has received grants for stigma-related research in the past 5 years from the National Institute for Health Research, and has acted as a consultant to the UK Office of the Chief Scientist.

\section{Copyright and usage}

(c) The Royal College of Psychiatrists 2017. This is an open access article distributed under the terms of the Creative commons Attribution (CC BY) licence.
Mental health-related stigma deters many people from seeking help for mental health problems and from disclosing to others. ${ }^{1,2}$ However, there is little evidence to date that programmes to reduce stigma can have an impact on these behaviours. ${ }^{3}$ The most suggestive evidence so far comes from the evaluation of 'The Nuremberg Alliance Against Depression', a two-year communitybased educational intervention involving three key messages: (a) depression can be treated; (b) depression has many faces; and (c) depression can affect everybody. ${ }^{4-6}$ There was a significant reduction in the number of suicidal acts during the campaign compared with a control-comparison region. ${ }^{4}$ However the mechanism for this effect is unknown, and could be related to better identification of depression by primary care physicians rather than increased help-seeking. The 'beyondblue' campaign in Australia also focuses on depression. Its differential uptake among states and territories initially allowed comparison of public attitudes between high and low exposure areas. ${ }^{7}$ This showed higher levels of agreement that antidepressants and professional interventions can be helpful in high exposure areas, again suggesting an impact of the campaign.

In England, the Time to Change (TTC) programme, launched in January 2009, aimed to improve public attitudes and to reduce discriminatory behaviour towards people with mental illness. ${ }^{8}$ TTC has been funded in three phases: 2007-2011; 2011-2015, with an additional year to 2016; and 2016-2021. The national social marketing campaign component of TTC uses bursts of mass-media advertising and public relations exercises. Its key messages are: (a) mental illnesses are common and people with such disorders can lead meaningful lives; (b) mental illness is our last taboo, such that the accompanying discrimination and exclusion can affect people in ways that many describe as worse than the illness itself; and (c) we can all do something to help people with mental illness. This call to action encourages people to support those they know with mental illness, for example by maintaining contact, and has been the main focus of the campaign since 2011. The campaign media targeted men and women aged 25-45 years, from middle socioeconomic groups. This age group was chosen because attitudes have been shown to be more entrenched in older individuals and younger adults may have less empathy. ${ }^{9}$ The campaign was aimed primarily at those with proximity to people with mental health problems, not as close family members, but as friends, colleagues and wider family. This includes a significant proportion of the public, who may influence other groups, and may have attitudes most amenable to a social marketing campaign.

During phases 1 and 2 there were two main bursts of social marketing activity per year using multiple media, supported by public relations and media work to maximise unfunded coverage. Campaign reach was extended by working with stakeholders (for example National Health Service (NHS) organisations) and making campaign materials freely available. Social media used included Facebook, Twitter, Spotify and You Tube. Advertising directed the target audience to the TTC website, which includes stories of people with mental health problems, tips on fighting stigma, blogs and forums. The campaign focused on behaviour change, using social media to prompt the target group to action, from small actions such as starting a conversation about mental health with a friend or co-worker to helping organise a local event 
aimed at engaging the community or organisations in fighting stigma and discrimination.

In phase 1 (2007-2011) projects for people with mental health problems comprised 28 local schemes promoting mental and physical well-being ${ }^{10}$ and 32 antidiscrimination initiatives. For targeted groups (medical students and trainee teachers), Education not Discrimination used contact-based education. ${ }^{11}$ Time to Challenge aimed to augment employers' knowledge of discrimination related to mental health with respect to employment and help people take legal action against organisations that have discriminated. From 2009, contact events were developed in partnership with local organisations to provide face-to-face opportunities to talk about mental health problems and to act on the messages delivered via the campaign. ${ }^{12}$ In phase 2 a separate programme was also delivered through schools and other settings aimed at children and young people. People with mental health problems became more involved in the delivery of contact events and in work with stakeholders such as employers.

Although the main target outcomes of TTC were to change attitudes and reduce discrimination, anti-stigma programmes should also aim to increase disclosure to those who can support someone with a mental health problem in their personal and work lives including supporting them to seek professional help. ${ }^{13,14}$ Moreover, in many countries disclosure to an employer is a legal prerequisite for accessing workplace adjustments to allow someone with a disability, in this case because of mental illness, to perform their job. ${ }^{15}$ Anti-stigma campaigns should also aim to help reduce the treatment gap by promoting professional help-seeking. For adults in the UK, free professional help for mental health problems requires a discussion with a general practitioner (GP). Mental healthcare is then accessed either within primary healthcare or through a referral from the GP to specialist mental health services. Willingness to seek help from a GP is thus critical for treatment. Regarding evidence for whether reducing stigma increases intentions to disclose or seek professional help, we have previously reported that relevant mental health knowledge predicts intentions to seek help for a mental illness and to disclose such an illness to family and friends, which underlines the importance of mental health literacy. ${ }^{16}$

Attitudes towards people with mental illness show a more mixed pattern with respect to help-seeking and disclosure intentions. A factor analysis of the shortened version of the Community Attitudes Toward the Mentally Ill (CAMI) scale, ${ }^{17}$ used in the Department of Health Attitudes to Mental Illness Survey, found two factors: 'tolerance and support for community care'; and 'prejudice and exclusion.' ${ }^{16}$ We found that intentions to seek help for a mental health problem are associated with attitudes of tolerance and support for community care, but not with stigmatising attitudes of prejudice and exclusion. ${ }^{16}$ These findings suggest that having strong positive attitudes might be more relevant to disclosure and help-seeking than whether negative attitudes are held. They further suggest that targeting these attitudes among the public may be an effective way to promote help-seeking, contrary to the conclusions drawn from a recent systematic review. ${ }^{18}$ This review concluded that perceived public stigma is not relevant to help-seeking intentions, however, many of the CAMI items in the 'tolerance and support for community care' factor address this aspect of stigma.

Analysis of the Attitudes to Mental Illness Survey data collected at the end of the first phase of TTC (2008-2011) found a relationship between campaign awareness and attitudes to mental illness as measured using the CAMI, but not with stigma-related mental health knowledge or desire for social distance. $^{9,19}$ We also did not find any relationship between campaign awareness and either comfort in disclosing to family and friends or intended help-seeking. ${ }^{20}$ At this point, the only clearly positive change over the course of TTC at the general population level was a reduced desire for social distance. ${ }^{9}$ However, within the social marketing campaign target group, ${ }^{21}$ i.e. those in middle-income groups aged $25-45$, we found positive relationships between campaign awareness and each of: knowledge; attitudes; and desire for social distance. Further, at the end of the second phase of TTC (2011-2016), we found improved stigma-related knowledge; improved attitudes; and reduced desire for social distance in the general population using the Attitudes to Mental Illness Survey. ${ }^{19}$ Therefore, the aims of this study were to examine whether, using data from the second phase of TTC, there is any association between awareness of TTC in the general public and each of: (a) comfort envisaged in disclosing a mental health problem to family and friends; (b) comfort envisaged in disclosing a mental health problem to an employer: and (c) intended professional help-seeking for a mental health problem.

\section{Method}

\section{Data source}

The Attitudes to Mental Illness survey is conducted by the agency Kantar TNS as part of an Omnibus Survey and has been carried out annually since 2008 as a part of the TTC evaluation. The area for its sampling frame is the same as the area covered by TTC, i.e. England. TTC received funding in October 2007, and the first events were run in October 2008, coinciding with World Mental Health Day. Nationally representative separate samples of approximately 1700 adults residing in England were surveyed each year from 2008 to $2016{ }^{19}$ From 2012 the survey has included questions to establish awareness of TTC, ${ }^{3}$ therefore this paper reports results from data collected 2012-2016. The survey is carried out using a quota sample, with locations for interviewing selected using a random methodology. Information from the UK Census and postal code areas were used to define interviewing locations, which were stratified by regions of England as defined by the UK Government Office, and social status.

Interviews were carried out in participants' homes by fully trained personnel using computer-assisted personal interviewing and demographic information was collected at the end of the interview. Additional information regarding the survey methods can be found in TNS BMRB. ${ }^{22}$ The research is exempted from research ethics approval by King's College London Psychiatry, Nursing and Midwifery Research Ethics Subcommittee as it comprises secondary analysis of an anonymised data-set.

\section{Measures}

\section{Questions on disclosure and help-seeking}

The survey includes one question: 'If you felt that you had a mental health problem, how likely would you be to go to your GP (general practitioner) for help?' with a five-point Likert scale of responses from 'very unlikely' to 'very likely'. Comfort in disclosing to others about a mental health problem is assessed using two questions. One asks about the respondent's level of comfort talking to a friend or family member about mental health, for example telling them about one's mental health diagnosis and its effect; the other asks the same question applied to talking to a current or prospective employer. Responses range from 'very uncomfortable' to 'very comfortable' on a seven-point Likert scale.

\section{Awareness of Time to Change}

The final survey questions required the interviewer to first show the respondent a card with a composite of material from all of 
the previous bursts of TTC social marketing activity. The interviewer then asked whether the respondent had seen any of the material and, if so, how many times. Awareness of TTC was dichotomised into 'any' $v$. 'none' for the analysis.

\section{Socioeconomic status}

Socioeconomic status of the respondent was categorised into one of four categories (i.e. $\mathrm{AB}, \mathrm{C} 1, \mathrm{C} 2$ and $\mathrm{DE}$ ) according to the Market Research Society's classification system. ${ }^{23}$ Classification was based on the occupation of the chief income earner in the household. Category $\mathrm{AB}$ represents individuals with professional/ managerial occupations, $\mathrm{C} 1$ represents individuals with other non-manual occupations, $\mathrm{C} 2$ represents individuals having skilled manual occupations and DE represents individuals with semi-/ unskilled manual occupations and people dependent on state benefits.

\section{Familiarity with mental health problems}

Previous research demonstrates that knowing someone with a mental health problem/familiarity with mental illness is strongly associated with mental health-related knowledge, attitudes and desire for social distance., ${ }^{9,19,24-26}$ We measured familiarity using the following item: who is the person closest to you who has or has had some kind of mental illness? Potential response options included: immediate family (e.g. spouse/child/sister/brother/parent), partner (living with you), partner (not living with you), other family (e.g. uncle/aunt/cousin/grandparent), friend, acquaintance, work colleague, self, other (please specify) and no one known. Responses were then categorised into three groups: self, other and none.

\section{Analysis}

To characterise our sample, basic sociodemographic data are described using relevant summary statistics, and potential underrepresentation of sociodemographic groups has been corrected though sample weighting of gender, age and ethnicity; this is consistent with previous TTC analyses. ${ }^{9,19}$

To investigate the association between awareness of TTC with the three questions on disclosure and help-seeking, three separate logistic regression models were performed using the corresponding questions as the outcome variables. The questions were dichotomised into binary responses: for the disclosure comfort questions, 'very comfortable', 'moderately comfortable' or 'fairly comfortable' were grouped together to reflect a positive response of 'somewhat comfortable with disclosing to friends and family or an employer'; and for the help-seeking question, the responses 'very likely' or 'quite likely' were grouped together to reflect a positive response of 'some likelihood of seeking help from a GP'. These positive outcomes were compared with all other (neutral or negative) responses.

To maintain consistency, all of the models included the covariates used in previous TTC regression modelling: ${ }^{9,19}$ year (categorical: 2012-2016); gender (female $v$. male); age (categorical: 16-24, 25-44, 45-64 and 65+); ethnicity (categorical: Asian, Black, other and White); socioeconomic status (categorical: AB, C1, C2 and $\mathrm{DE}$ ); and familiarity with mental health problems (categorical: self, other and none). Awareness of TTC was then included as an additional covariate in the form of a binary variable, campaign awareness, as explained above (any $v$. none). These demographic variables are associated with help-seeking for mental health problems in primary care ${ }^{27}$ and we previously found all the variables to be associated with stigma outcomes i.e. mental health-related knowledge, attitudes and desire for social distance.
For the question on comfort disclosing to a current or prospective employer, the oldest age group was removed as this is not relevant to the majority of people aged 65 or over.

For many of those replying 'self' to the familiarity with mental health problems question, decisions to seek help from a GP or to disclose are likely to have been taken already. However, the questions are still applicable regarding future help-seeking, for example for a recurrence of a mental health problem, and future disclosure, for example to a different employer or to family or friends to whom the person has yet to disclose. We therefore left this group in for all three models. All analyses were carried out using Stata version 14.

\section{Results}

The sample included $48.8 \%$ men and $51.2 \%$ women and the mean age was approximately 46 years, ranging from 16 to 98 years of age $($ s.d. = 18.9). The whole sample had slightly higher representation of individuals in lower socioeconomic classes compared with individuals from middle and upper socioeconomic classes to allow analysis by socioeconomic group; this has been corrected through sample weighting. Table 1 shows unweighted frequencies and weighted percentages of the characteristics of survey participants by year and Table 2 shows their responses regarding awareness of TTC, intended help-seeking from primary care and comfort in disclosing.

Table 3 shows responses regarding intended help-seeking and disclosure comfort by campaign awareness. Comfort in disclosure to an employer was lowest, at $38.8 \%$ for those who were campaign aware and $35.0 \%$ for those who were not. Comfort in disclosure to family and friends was higher at $72.6 \%$ for those who were campaign aware and $66.5 \%$ for those who were not. The intention to seek help from a GP was highest at $83.6 \%$ for those who were campaign aware and $80.6 \%$ for those who were not.

Table 4 shows results of logistic regression analyses, examining the relationship between campaign awareness and each of: intended help-seeking, comfort disclosing to family and friends, and comfort disclosing to an employer, controlling for sociodemographic characteristics and familiarity with mental health problems. We found positive relationships between campaign awareness and all of: likelihood of help-seeking (odds ratio $(\mathrm{OR})=1.18,95 \%$ CI 1.03-1.36); feeling comfortable disclosing a mental health problem to family and friends (OR $=1.27,95 \%$ CI 1.14-1.43) and feeling comfortable disclosing a mental health problem to a current or prospective employer $(\mathrm{OR}=1.20,95 \%$ CI 1.06-1.35).

Campaign awareness was the only independent variable significantly associated with the dependent variable for all three adjusted models. Survey year 2016 was significantly associated with lower intentions to seek help from a GP as compared with the reference year 2012 (OR $=0.76,95 \%$ CI 0.63-0.92); 2013 was significantly associated with less comfort in disclosing to friends or family $(\mathrm{OR}=0.76,95 \% \mathrm{CI} 0.65-0.89)$; and no survey year was associated with predicted comfort in disclosing to an employer. Female gender was associated with reduced comfort regarding disclosure to an employer ( $\mathrm{OR}=0.88,95 \%$ CI 0.79 0.98 ) but significantly positively associated with intentions to seek help from a GP $(\mathrm{OR}=1.33,95 \% \mathrm{CI} 1.18-1.50)$ and to disclose to friends or family $(\mathrm{OR}=1.28,95 \%$ CI 1.16-1.42). Being aged 16-44 was significantly associated with lower intentions to seek help from a GP compared with being aged 65 or over (OR for $16-24=0.48,95 \%$ CI $0.40-0.59$; OR for $25-44=0.60,95 \%$ CI $0.51-0.71$ ); being $45-64$ was significantly associated with feeling 


\begin{tabular}{|c|c|c|c|c|c|}
\hline & $\begin{array}{c}2012 \\
(n=1717)\end{array}$ & $\begin{array}{c}2013 \\
(n=1727)\end{array}$ & $\begin{array}{c}2014 \\
(n=1714)\end{array}$ & $\begin{array}{c}2015 \\
(n=1736)\end{array}$ & $\begin{array}{c}2016 \\
(n=1765)\end{array}$ \\
\hline \multicolumn{6}{|l|}{ Gender } \\
\hline Female & $924(51.3)$ & $926(51.0)$ & $893(50.9)$ & 919 (51.6) & $918(51.4)$ \\
\hline Male & $793(48.7)$ & $801(49.0)$ & $821(49.1)$ & $817(48.4)$ & $847(48.6)$ \\
\hline Age, years: mean (s.d.) & $46.4(19.1)$ & 45.9 (18.3) & $46.0(18.8)$ & $46.4(19.2)$ & $46.3(19.0)$ \\
\hline \multicolumn{6}{|l|}{ Age group } \\
\hline $16-24$ & $258(14.6)$ & $289(14.6)$ & $221(14.4)$ & $242(14.1)$ & $211(13.6)$ \\
\hline $25-44$ & $580(34.8)$ & $568(36.1)$ & $514(36.2)$ & $528(35.3)$ & $597(35.5)$ \\
\hline $45-64$ & $506(31.3)$ & $486(31.1)$ & $506(30.6)$ & $488(31.5)$ & $488(31.7)$ \\
\hline $65+$ & 373 (19.3) & $384(18.3)$ & $473(18.7)$ & $478(19.0)$ & 469 (19.3) \\
\hline \multicolumn{6}{|l|}{ Ethnicity } \\
\hline Asian & $160(9.7)$ & $127(7.9)$ & $105(6.6)$ & $120(6.7)$ & $121(7.0)$ \\
\hline Black & $67(3.8)$ & $66(3.7)$ & $69(4.0)$ & $99(5.3)$ & $83(4.7)$ \\
\hline Other & $31(1.8)$ & $44(2.6)$ & $26(1.6)$ & $39(2.3)$ & $42(2.6)$ \\
\hline White & 1449 (84.7) & 1474 (85.9) & $1507(87.8)$ & $1472(85.7)$ & $1507(85.7)$ \\
\hline \multicolumn{6}{|l|}{ Socioeconomic status ${ }^{a}$} \\
\hline$A B$ & $292(19.3)$ & $302(20.5)$ & $353(21.4)$ & $335(22.2)$ & $271(18.9)$ \\
\hline $\mathrm{C} 1$ & $456(31.0)$ & $445(30.4)$ & $457(29.2)$ & $432(28.4)$ & $430(30.6)$ \\
\hline $\mathrm{C} 2$ & $368(21.6)$ & $362(20.8)$ & $333(20.5)$ & $354(20.4)$ & $371(20.7)$ \\
\hline DE & $601(28.1)$ & $618(29.1)$ & $571(29.0)$ & $615(29.1)$ & $693(29.8)$ \\
\hline \multicolumn{6}{|c|}{ Familiar with mental health problems } \\
\hline Self & $111(6.4)$ & $120(6.6)$ & $126(7.4)$ & $124(6.9)$ & $124(7.4)$ \\
\hline Other & $926(55.9)$ & $963(57.9)$ & $953(57.5)$ & $963(58.1)$ & $1013(61.1)$ \\
\hline None & $645(37.7)$ & $610(35.5)$ & $606(35.1)$ & $632(35.0)$ & $586(31.5)$ \\
\hline
\end{tabular}

\begin{tabular}{|c|c|c|c|c|c|}
\hline & $\begin{array}{c}2012 \\
(n=1717)\end{array}$ & $\begin{array}{c}2013 \\
(n=1727)\end{array}$ & $\begin{array}{c}2014 \\
(n=1714)\end{array}$ & $\begin{array}{c}2015 \\
(n=1736)\end{array}$ & $\begin{array}{c}2016 \\
(n=1765)\end{array}$ \\
\hline \multicolumn{6}{|l|}{ Campaign awareness } \\
\hline Aware & $497(29.1)$ & $745(43.3)$ & $320(20.2)$ & $479(29.1)$ & $388(23.6)$ \\
\hline Not aware & $1220(70.9)$ & $982(56.6)$ & $1394(79.8)$ & $1257(70.9)$ & $1377(76.4)$ \\
\hline \multicolumn{6}{|c|}{ Seek help from general practitioner } \\
\hline Likely & $1431(82.7)$ & $1426(81.9)$ & $1446(83.7)$ & $1425(81.7)$ & $1367(77.7)$ \\
\hline Neutral or not likely & $286(17.3)$ & $301(18.1)$ & $268(16.3)$ & $311(18.3)$ & $398(22.3)$ \\
\hline \multicolumn{6}{|l|}{ Disclose to friends/family } \\
\hline Comfortable & $1214(69.9)$ & $1114(64.4)$ & $1205(70.3)$ & $1191(68.9)$ & $1178(67.7)$ \\
\hline Neutral or not comfortable & $503(30.1)$ & $613(35.6)$ & $509(29.7)$ & $545(31.1)$ & $587(32.3)$ \\
\hline \multicolumn{6}{|l|}{ Disclose to employer ( $<65$ years) } \\
\hline Comfortable & $495(36.6)$ & $452(33.6)$ & $447(36.3)$ & $492(38.6)$ & $456(35.5)$ \\
\hline Neutral or not comfortable & $849(63.4)$ & $891(66.4)$ & $794(63.7)$ & $766(61.4)$ & $840(64.5)$ \\
\hline
\end{tabular}

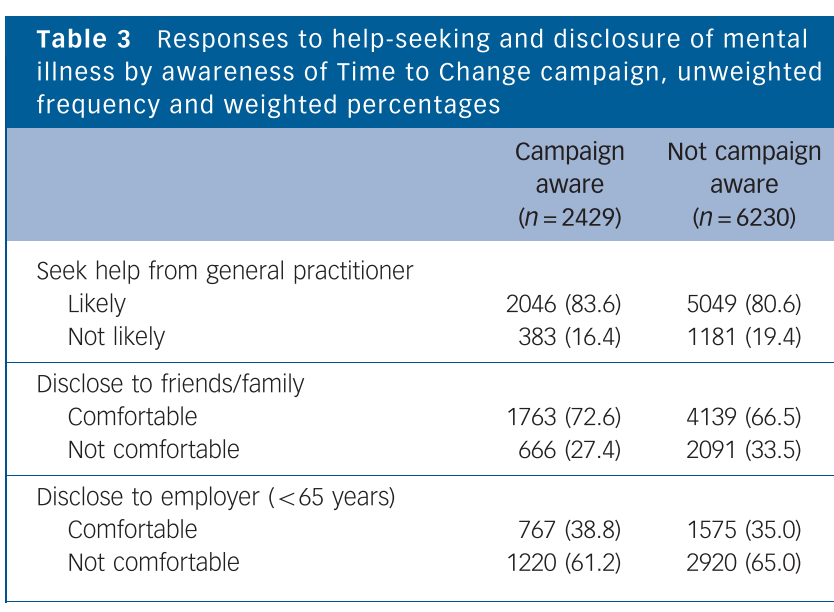

comfortable disclosing to family or friends compared with older and younger age groups $(\mathrm{OR}=1.21,95 \% \mathrm{CI} 1.05-1.38)$.

Socioeconomic status, as defined by occupational status, was not significantly associated with intended help-seeking from a GP or disclosing to friends/family, however respondents in the highest socioeconomic group $(\mathrm{AB})$ were significantly less likely to state they would feel comfortable disclosing to an employer $(\mathrm{OR}=0.78,95 \%$ CI $0.66-0.92)$. Having experienced a mental health problem significantly predicted both likelihood of helpseeking $(\mathrm{OR}=1.82,95 \% \mathrm{CI} 1.36-2.43)$ and of comfort disclosing to family or friends $(\mathrm{OR}=1.32,95 \%$ CI $1.06-1.63)$, but not comfort in disclosing to an employer; knowing someone else with a mental health problem was only a significant predictor of comfort in disclosing to family or friends $(\mathrm{OR}=1.24,95 \% 1.11-$ 1.39). There was no relationship between ethnicity and responses to any of the questions. There were no significant interactions 
Table 4 Logistic regression analyses of predictors of disclosure and help-seeking in mental illness

\begin{tabular}{|c|c|c|c|c|c|c|}
\hline \multirow[b]{2}{*}{ Predictors } & \multicolumn{2}{|c|}{$\begin{array}{l}\text { Disclosing to friends or family } \\
\qquad(n=8455)\end{array}$} & \multicolumn{2}{|c|}{$\begin{array}{l}\text { Disclosing to a current or prospective } \\
\text { employer for those }<65 \text { years }(n=6325)\end{array}$} & \multicolumn{2}{|c|}{$\begin{array}{l}\text { Intended help-seeking from a general } \\
\text { practitioner }(n=8455)\end{array}$} \\
\hline & Adjusted OR (95\% Cl) & $P$ & Adjusted OR (95\% Cl) & $P$ & Adjusted OR (95\% Cl) & $P$ \\
\hline \multicolumn{7}{|c|}{ Campaign awareness } \\
\hline Aware & $1.27(1.14-1.43)^{\star}$ & $<0.001$ & $1.20(1.06-1.35)^{*}$ & 0.003 & $1.18(1.03-1.36)^{\star}$ & 0.020 \\
\hline Not aware (ref) & - & - & - & - & - & - \\
\hline \multicolumn{7}{|l|}{ Year } \\
\hline 2016 & $0.92(0.79-1.08)$ & 0.324 & $0.98(0.83-1.16)$ & 0.806 & $0.76(0.63-0.92)^{*}$ & 0.004 \\
\hline 2015 & $0.94(0.81-1.11)$ & 0.474 & $1.10(0.93-1.30)$ & 0.278 & $0.93(0.77-1.13)$ & 0.485 \\
\hline 2014 & $1.06(0.90-1.24)$ & 0.502 & $1.01(0.85-1.20)$ & 0.874 & $1.13(0.92-1.38)$ & 0.235 \\
\hline 2013 & $0.76(0.65-0.89)^{*}$ & 0.001 & $0.87(0.74-1.03)$ & 0.109 & $0.95(0.78-1.15)$ & 0.579 \\
\hline 2012 (ref) & - & - & - & - & - & - \\
\hline \multicolumn{7}{|l|}{ Gender } \\
\hline Female & $1.28(1.16-1.42)^{\star}$ & $<0.001$ & $0.88(0.79-0.98)^{*}$ & 0.019 & $1.33(1.18-1.50)^{\star}$ & $<0.001$ \\
\hline Male (ref) & - & - & - & - & - & - \\
\hline \multicolumn{7}{|l|}{ Age } \\
\hline $16-24$ & $1.05(0.89-1.24)$ & 0.529 & $1.02(0.87-1.19)$ & 0.853 & $0.48(0.40-0.59)^{*}$ & $<0.001$ \\
\hline $25-44$ & $1.03(0.90-1.17)$ & 0.668 & $1.06(0.94-1.20)$ & 0.320 & $0.60(0.51-0.71)^{\star}$ & $<0.001$ \\
\hline $45-64(\text { ref })^{a}$ & $1.21(1.05-1.38)^{\star}$ & 0.006 & - & - & $0.88(0.73-1.04)$ & 0.135 \\
\hline $65+($ ref) & - & - & NA & NA & - & - \\
\hline \multicolumn{7}{|l|}{ Ethnicity } \\
\hline Asian & $0.96(0.79-1.16)$ & 0.660 & $1.17(0.97-1.42)$ & 0.103 & $1.19(0.94-1.51)$ & 0.143 \\
\hline Black & $0.93(0.73-1.18)$ & 0.558 & $1.12(0.87-1.43)$ & 0.380 & $0.93(0.70-1.25)$ & 0.646 \\
\hline Other & $0.87(0.63-1.21)$ & 0.420 & $1.01(0.72-1.43)$ & 0.936 & $0.88(0.61-1.29)$ & 0.524 \\
\hline White (ref) & - & - & - & - & - & - \\
\hline \multicolumn{7}{|c|}{ Socioeconomic status ${ }^{b}$} \\
\hline$A B$ & $0.96(0.83-1.11)$ & 0.574 & $0.78(0.66-0.92)^{\star}$ & 0.004 & $1.01(0.85-1.22)$ & 0.880 \\
\hline $\mathrm{C} 1$ & $1.11(0.98-1.26)$ & 0.096 & $0.98(0.86-1.13)$ & 0.809 & $0.94(0.80-1.09)$ & 0.411 \\
\hline $\mathrm{C} 2$ & $1.03(0.90-1.17)$ & 0.716 & $1.10(0.95-1.27)$ & 0.220 & $1.05(0.88-1.24)$ & 0.607 \\
\hline DE (ref) & - & - & - & - & - & - \\
\hline \multicolumn{7}{|c|}{$\begin{array}{l}\text { Familiarity with mental } \\
\text { health problems }\end{array}$} \\
\hline Self & $1.32(1.06-1.63)^{\star}$ & 0.011 & $1.07(0.86-1.34)$ & 0.524 & $1.82(1.36-2.43)^{\star}$ & $<0.001$ \\
\hline Other & $1.24(1.11-1.39)^{*}$ & $<0.001$ & $1.02(0.90-1.16)$ & 0.722 & $1.00(0.88-1.15)^{\star}$ & 0.958 \\
\hline None (ref) & - & - & - & - & - & - \\
\hline \multicolumn{7}{|c|}{$\begin{array}{l}\text { Ref, reference category; NA, not applicable. } \\
\text { a. Age group } 45-64 \text { was used as the reference category for disclosing to a current or prospective employer for those }<65 \text { years. } \\
\text { b. Category AB, professional/managerial occupations; } C 1 \text {, other non-manual occupations; } C 2 \text {, skilled manual occupations; and DE, semi-/unskilled manual occupations and people } \\
\text { dependent on state benefits. } \\
\text { * Significant at the } P<0.05 \text { level. }\end{array}$} \\
\hline
\end{tabular}

between year and campaign awareness, and therefore no evidence that the impact of campaign awareness on the behavioural intentions measured has changed over time.

\section{Discussion}

For those surveyed during the second phase of TTC (2012-2016) we found relationships between awareness of the campaign and each of: likelihood of seeking help for a mental health problem from a GP; feeling comfortable disclosing a mental health problem to family and friends and feeling comfortable disclosing a mental health problem to a current or prospective employer. This was the only consistent predictor across all three questions; in the case of both sociodemographic variables and familiarity with mental health problems, predictors varied depending on the question.

With respect to help-seeking in primary care, the associated sociodemographic variables are consistent with other studies on use of primary care for mental disorders, ${ }^{27}$ with the exception of a recent finding in a Canadian sample in which younger patients, both male and female were more willing to seek primary care in response to mental health problems compared with older patients. ${ }^{28}$ For those in professional or managerial occupations or in households in which the main earner has such an occupation, reduced comfort in disclosure to an employer might reflect a greater perceived risk $v$. potential benefits. This might include being unable to continue in an occupation that requires lengthy training $^{24}$ or greater anticipation of workplace discrimination. ${ }^{29}$ The results are consistent with a survey across the UK and six other European countries that found that university-educated employees were less likely to disclose to an employer or take time off work because of depression. ${ }^{30}$ Anticipated discrimination in the workplace may also contribute to women's greater discomfort with workplace disclosure of a mental health problem, given their awareness of gender discrimination as an additional risk. For people familiar with someone with a mental health problem, greater comfort in disclosure to family or friends suggests an expectation of reciprocity within supportive relationships, but this does not transfer to an effect on likelihood of professional help-seeking; the latter is only increased in those with personal experience, which for many will include that of prior help-seeking.

The results regarding year of the survey are more difficult to interpret. Given that we included campaign awareness in the model, these results may reflect other events or secular trends. For example, being less likely to seek help from a GP in the final survey year may reflect the increase in general difficulty accessing primary care in many parts of England ${ }^{31}$ during a period of continuing economic austerity related to funding of the NHS. 


\section{Strengths and limitations of the study}

This study used a large nationally representative data-set that included baseline measures specifically targeted and developed for the evaluation of the TTC programme. Despite these strengths, there are some limitations associated with this study. We did not collect information about awareness of the TTC campaign in years 2009-2011 of this survey and thus we only know the extent to which campaign awareness is associated with the outcomes examined here, as well as with each of knowledge, attitudes and behaviour, in the later years. Questions about awareness were added to the end of the survey to avoid biasing responses to the outcome measures. As data are collected face to face, we cannot be sure to what extent social desirability affected responses; further, awareness of TTC may increase the effect on the measures of social desirability. ${ }^{32}$ Finally, the evaluation does not distinguish responses regarding common mental disorders, with which respondents are more likely to be familiar, from responses regarding less prevalent illnesses.

\section{Implications}

These findings provide support for the effectiveness of the TTC national anti-stigma programme in increasing intended help-seeking within primary healthcare and in increasing people's comfort regarding disclosure to family, friends and employers. Further work is required to understand the effective ingredients of TTC, including the extent to which behavioural intentions are mediated by mental health-related knowledge and/or attitudes, and the relative importance of specific components of attitudes such as personal attitudes $v$. perceived public stigma, ${ }^{18}$ both of which TTC has addressed. It will also be critical to determine whether its impact is sustained beyond its duration.

The proportions of the population aware of the campaign over the survey period ranged from 20 to $44 \%$, thus the majority of the population are not directly affected by it. Campaign awareness was affected by whether or not television was used, for example in 2013, as its high cost precluded its use for every burst. Changes in the delivery of the campaign may be needed to extend its reach, or other methods will be needed to achieve whole population change.

The results highlight the greater barriers for particular sociodemographic groups with respect to professional help-seeking, suggesting the need for more tailored interventions to encourage help-seeking within primary care. They also demonstrate the need for workplace interventions to encourage disclosure to employers when this is needed to access support or reasonable adjustments. In addition to clear messages from employers that discrimination against people with mental health problems will not be tolerated, and action to follow through on this commitment, employees may benefit from decision aids ${ }^{33}$ regarding disclosure and help-seeking tailored to their profession or occupational group.

In addition to providing support, family, friends, health professionals and employers are sources of discrimination, as has been found in both general population ${ }^{34,35}$ and clinical ${ }^{25,36}$ samples. Discomfort with the idea of disclosing is therefore understandable for many people, as disclosure tends to be accompanied by a mix of both positive and negative experiences. ${ }^{34,35}$ It therefore seems likely that an increased likelihood of help-seeking and comfort in disclosing will only follow reductions in the frequencies of discrimination. Such reductions have been observed over the course of TTC as reported by mental health service users, on the part of family, friends and employers, but not for health professionals outside the setting of mental healthcare. ${ }^{36}$ Discrimination by health professionals typically manifests as the experience of being treated dismissively, being judged and not being listened to. ${ }^{34}$ Contact-based education for health professionals in Canada has been shown to be effective in improving their attitudes to mental illness at least in the short term, ${ }^{26}$ as has education about problems they find especially difficult, such as self-harm and substance use. ${ }^{37}$ Research is now needed to determine whether discrimination by health professionals can be reduced and what impact this has on helpseeking.

Claire Henderson, MRCPsych, PhD, Health Service and Population Research Department, King's College London, Institute of Psychiatry, Psychology and Neuroscience, London; Emily Robinson, MSc, Biostatistics \& Health Informatics Department, King's College London, Institute of Psychiatry, Psychology and Neuroscience, London; Sara Evans-Lacko, PhD, Graham Thornicroft, PhD, FRCPsych, Health Service and Population Research Department, King's College London, Institute of Psychiatry, Psychology and Neuroscience, London, UK

Correspondence: Claire Henderson, MRCPsych, PhD, Clinical Senior Lecturer in Psychiatry Health Services and Population Research Department P029, David Goldberg Centre, King's College London, Institute of Psychiatry, Psychology and Neuroscience, De Crespigny Park, London SE5 8AF, UK. Email:

Claire.1.Henderson@kcl.ac.uk

First received 11 Nov 2016, final revision 27 Apr 2017, accepted 26 May 2017

\section{Funding}

The Time to Change evaluation was funded by the UK Government Department of Health, Comic Relief and Big Lottery Fund. C.H., E.R. and S.E.-L. were supported during phase 2 of TTC by grants to TTC from the UK Department of Health and Comic Relief. C.H. was also funded by grants from the National Institute for Health Research (NIHR), Maudsley Charity and Guy's and St Thomas's Charity. G.T. is supported by the European Union Seventh Eramework Programme (FP7/2007-2013) Emerald project. G.T. acknowledges financial arch Centre and Dementia Unit awarded to South London and Maudsley NHS Foundation Trust in partnership with King's College London and King's College Hospital NHS Foundation Trust. G.T. acknowledges support from the NIHR Collaboration for Leadership in Applied Health Research and Care South London at King's College London Foundation Trust. The views sexpressed are those of the author(s) and not necessarily those of the NHS, the NIHR or the Department of Health.

\section{Acknowledgements}

We are grateful for collaboration on the evaluation by: Sue Baker and Paul Farmer.

\section{References}

1 Clement S, Schauman O, Graham T, Maggioni F, Evans-Lacko S, Bezborodov $\mathrm{N}$, et al. What is the impact of mental health related stigma on help-seeking? A systematic review of quantitative and qualitative studies. Psychol Med 2015; 45: 11-27.

2 Brohan E, Henderson C, Wheat K, Malcolm E, Clement S, Barley EA, et al. Systematic review of beliefs, behaviours and influencing factors associated with disclosure of a mental health problem in the workplace. BMC Psychiatry 2012; 12: 11 .

3 Henderson C, Evans-Lacko S, Thornicroft G. Mental illness stigma, helpseeking and public health programmes. Am J Public Health 2013; 103: 777-80.

4 Hegerl U, Althaus D, Schmidtke A, Niklewski G. The alliance against depression: 2-year evaluation of a community-based intervention to reduce suicidality. Psychol Med 2006; 36: 1225-34.

5 Hegerl U, Althaus D, Stefanek J. Public attitudes towards treatment of depression: effects of an information campaign. Pharmacopsychiatry 2003; 36: 288-91.

6 Dietrich S, Mergl R, Freudenberg P, Althaus D, Hegerl U. Impact of a campaign on the public's attitudes towards depression. Health Educ Res 2010; 25: 135-50.

7 Jorm AF, Christensen $\mathrm{H}$, Griffiths KM. The impact of beyondblue: the national depression initiative on the Australian public's recognition of depression and beliefs about treatments. Aust NZ J Psychiatry 2005; 39: 248-54.

8 Henderson $C$, Thornicroft G. Stigma and discrimination in mental illness: Time to Change. Lancet 2009; 373: 1928-30.

9 Evans-Lacko S, Henderson C, Thornicroft G. Public knowledge, attitudes and behaviour regarding people with mental illness in England 2009-2012. Br J Psychiatry 2013; 202: s51-7. 
10 Malcolm E, Evans-Lacko S, Little K, Henderson C, Thornicroft G. The impact of exercise projects to promote mental wellbeing. J Ment Health 2013; 22: 519-27.

11 Friedrich B, Evans-Lacko S, London J, Rhydderch D, Henderson C, Thornicroft G. Anti-stigma training for medical students - the Education Not Discrimination project. Br J Psychiatry 2013; 202 (suppl 55): s89-94.

12 Evans-Lacko S, London J, Japhet S, Rusch N, Flach C, Corker E, et al. Mass social contact interventions and their effect on mental health related stigma and intended discrimination. BMC Public Health 2012; 12: 489.

13 Del Vecchio V, Luciano M, Sampogna G, De Rosa C, Giacco D, Tarricone I, et al. The role of relatives in pathways to care of patients with a first episode of psychosis. Int J Soc Psychiatry 2015; 61: 631-7.

14 Brohan E, Evans-Lacko S, Henderson C, Murray J, Slade M, Thornicroft G. Disclosure of a mental health problem in the employment context: qualitative study of beliefs and experiences. Epidemiol Psychiatr Sci 2014; 23: 289-300.

15 Lockwood G, Henderson C, Thornicroft G. The Equality Act 2010 and menta health. Br J Psychiatry 2012; 200: 182-3.

16 Rusch N, Evans-Lacko SE, Henderson C, Flach C, Thornicroft G. Knowledge and attitudes as predictors of intentions to seek help for and disclose a mental illness. Psychiatr Serv 2011; 62: 675-8.

17 Taylor SM, Dear MJ. Scaling community attitudes toward the mentally ill. Schizophr Bull 1981; 7: 225-40.

18 Schnyder N, Panczak R, Groth N, Schultze-Lutter F. Association between mental health-related stigma and active help-seeking: systematic review and meta-analysis. Br J Psychiatry 2017; 210: 261-8.

19 Henderson C, Robinson E, Evans-Lacko S, Corker E, Rebollo-Mesa I, Rose D, et al. Public knowledge, attitudes, social distance and reported contact regarding people with mental illness 2009-2015. Acta Psychiatr Scand 2016; 134: $23-33$

20 Henderson C, Evans-Lacko S, Thornicroft G. Mental illness stigma, helpseeking and public health programmes. Am J Public Health 2013; 103 : 777-80.

21 Evans-Lacko S, Malcolm E, West K, Rose D, London J, Rüsch N, et al. Influence of Time to Change's social marketing interventions on stigma in England 2009-2011. Br J Psychiatry 2013; 202: s77-88.

22 TNS BMRB. Attituds to Mental Illness: 2014 Research Report. TNS BMRB, 2015 (https://www.time-to-change.org.uk/sites/default/files/ Attitudes_to_mental_illness_2014_report_final_0.pdf).

23 Market Research Society. Social Grade: Census output on approximated social grade. MRS, 2017.

24 Cohen D, Winstanley SJ, Greene G. Understanding doctors' attitudes towards self-disclosure of mental ill health. Occup Med 2016; 66: 383-9.
25 Hamilton S, Pinfold V, Cotney J, Couperthwaite L, Matthews J, Barret K, et al. Qualitative analysis of mental health service users' reported experiences of discrimination. Acta Psychiatr Scand 2016; 134: 14-22.

26 Knaak S, Modgill G, Patten SB. Key ingredients of anti-stigma programs for health care providers: a data synthesis of evaluative studies. Can J Psychiatry 2014; 59 (suppl 1): S19-26.

27 McManus S, Jenkins R, Brugha T, Bebbington P (eds). Mental Health and Wellbeing in England: Adult Psychiatric Morbidity Survey 2014. NHS Digital, 2016.

28 Thompson $A E$, Anisimowicz $Y$, Miedema B, Hogg W, Wodchis WP, Aubrey-Bassler $\mathrm{K}$. The influence of gender and other patient characteristics on health care-seeking behaviour: a QUALICOPC study. BMC Fam Pract 2016; 17: 38 .

29 Ellison $\mathrm{ML}$, Russinova Z, MacDonald-Wilson $\mathrm{KL}$, Lyass A. Patterns and correlates of workplace disclosure among professionals and managers with psychiatric conditions. J Vocat Rehabil 2003; 18: 3-13.

30 Evans-Lacko S, Knapp M. Importance of social and cultural factors for attitudes, disclosure and time off work for depression: findings from a seven country European study on depression in the workplace. PloS One 2014; 9: e91053.

31 Cowling T, Cecil EV, Soljak MA, Lee JT, Millett C, Majeed A, et al. Access to primary care and visits to emergency departments in England: a crosssectional, population-based study. PloS One 2013; 8: e66699.

32 Henderson C, Evans-Lacko S, Flach C, Thornicroft G. Responses to mental health stigma questions: the importance of social desirability and data collection method. Can J Psychiatry 2012; 57: 152-60.

33 Henderson $C$, Brohan $E$, Clement $S$, Williams $P$, Lassman F, Schauman O, et al. Decision aid on disclosure of mental health status to an employer: feasibility and outcomes of a randomised controlled trial. Br J Psychiatry 2013; 203: 350-7.

34 Morgan AJ, Reavley NJ, Jorm AF, Beatson R. Experiences of discrimination and positive treatment from health professionals: a national survey of adults with mental health problems. Aust NZ J Psychiatry 2016; 50: 754-62.

35 Reavley NJ, Jorm AF. Experiences of discrimination and positive treatment in people with mental health problems: Findings from an Australian national survey. Aust NZ J Psychiatry 2015; 49: 906-13.

36 Corker E, Hamilton S, Robinson E, Cotney J, Pinfold V, Rose D, et al. Viewpoint survey of mental health service users' experiences of discrimination in England 2008-2014. Acta Psychiatr Scand 2016; 134: 6-13.

37 Henderson C, Noblett J, Parke $\mathrm{H}$, Clement S, Caffrey A, Gale-Grant O, et al Mental health-related stigma in health care and mental health-care settings. Lancet Psychiatry 2014; 1: 467-82. 